\title{
Native Advertising: Challenges and Perspectives
}

\author{
Bassant Eyada $^{1}$, Asli Cazorla Milla ${ }^{2}$
}

1- Associate Professor - American University in the Emirates

2- Assistant Professor - American University in the Emirates

\section{KEY WORDS:}

Advertising, Native Advertising, Consumer Behavior,Content Marketing, Social Media.

\begin{abstract}
:
Native advertising is a form of communication for brands, products or service to promote and engage target audience, designed to blend in the page content, consistent with general perspective of the designated page and media platform.

With no doubt, native advertising is growing to become an important part of the revenue for publishers, as more media companies are integrating it into their business models.

This paper explores the nature of native advertising, the rules and regulations that guide this form of advertising, and its impact on consumer behavior.
\end{abstract}

\section{INTRODUCTION:}

Native advertising is considered more of a partnership than just a promotion, where traditional forms of advertising stand out to the consumer, the main purpose of native advertising is to position the brand or service as a partner for the target audience, designed to blend with the designated page content, the general aspect of the page, and the intended media platform. This idea of partnership has led to a shift in the advertising strategies, as native ads depend on content marketing to position the product as a partner for the consumers rather than playing the role of the promoter, acting as an integrated source of information surrounding the existing content, not as an interruptive.

Native advertising offers marketers a more effective way to engage with consumers, which is proven through higher click through rates than traditional banner ads, particularly through mobile devices (Hoelzel, 2015). Having a history that goes back to the 1920s, native advertising has gained a wide interest among researchers within the last decade due to the increase of social media penetration, being affected by two main phenomenas causing a huge debate: consumer engagement and its ROI, and the process of content creation. Making it crucial for advertisers to understand that the consumers are becoming more sceptic as they decide what they want to see and interact with, hence, native advertising must look and feel like it belongs to and resonates with the consumers, and with the content surrounding it.

\section{What is Native Advertising}

Native advertising is a new concept of promoting brands, products or services. It is a form of advertising camouflaged as news content such as sponsored posts, search engine marketing, print news stories that are sponsored or promoted by a specific brand, or appear on social media. The main aim of native advertising is consumer engagement with existing content relevant infor- 
mation. The idea of native advertising has been long used seen and heard on TV and radio channels appearing as brand sponsored programs, the existence and increased use of social media and mobile media has given it larger advances, being also known as content marketing or sponsored content.

Appearing in different shapes and sizes, native advertising exists on social and search sites as a form of paid advertising where the ad bouts the form and function of the media content in which it appears. According to Wojdynski and Evans, the persuasion knowledge model suggests that consumers ability to effectively cope with advertising messages is predictable on the recognition of the persuasive nature of the messages. Evidence from research in television product placement suggests that disclosing such content in advertising affects the use of persuasion knowledge only for consumers who pay visual attention to the content and who effectively recall the disclosure content (Wojdynski and Evans, 2016).

With the rise of social media and the reliance on internet as main source of information, products are having a window to market themselves to uncountable number of consumers at a very little cost. Changing what the publications are offering to the advertisers, digital media has played a leading role in changing the marketing game from two main perspectives, becoming the most cost effective form of promotion for a product, and increased reach with wider and easier distribution of the ad with platforms that allow the ads to reach consumers internationally, causing social media to be the flawless environment for native advertising. A study conducted by Native Advertising Institute shows that the average native advertising share of total revenues has increased from $11 \%$ in 2015 to $25 \%$ in 2018 , with an expected increase for $32 \%$ of the total ad sales in 2020 (Laursen, 2017). Based on the IAB Europe's AdEx Benchmark 2017 report, native advertising is expected to reach $\$ 85.5$ billion by 2020 . (iabeurope.eu)

\section{History of Native Advertising}

The rise of the TV and radio industry in the 1920s is considered as a major donor to the existence and growth of native advertising, where several businesses sponsored radio programs to sustain their advertising spots, one of the most famous radio programs was The Eveready Hour which was the first sponsored radio program in the history of broadcasting in New York, premiering November 1923. Being radio's first sponsored program paid by the National Carbon Company which owned the Eveready Battery industry.

In 1930, the American company Proctor and Gamble (P\&G) founded 1837, was one of the first companies to sponsor daytime drama on the radio, to advertise their products to housewives. As their products are mainly soaps, the sponsored dramas were then known as "soap operas".

Print native advertising has as well recorded a long history, in 1915 Cadillac Cars Company sponsored an article at the Saturday Evening Post entitled "The Penalty of Leadership" about a superior man who leads a pack and endeavors greatness. While the article did not advertise Cadillac, but it was clear that the superiors are driving $\mathrm{Ca}$ dillacs. 


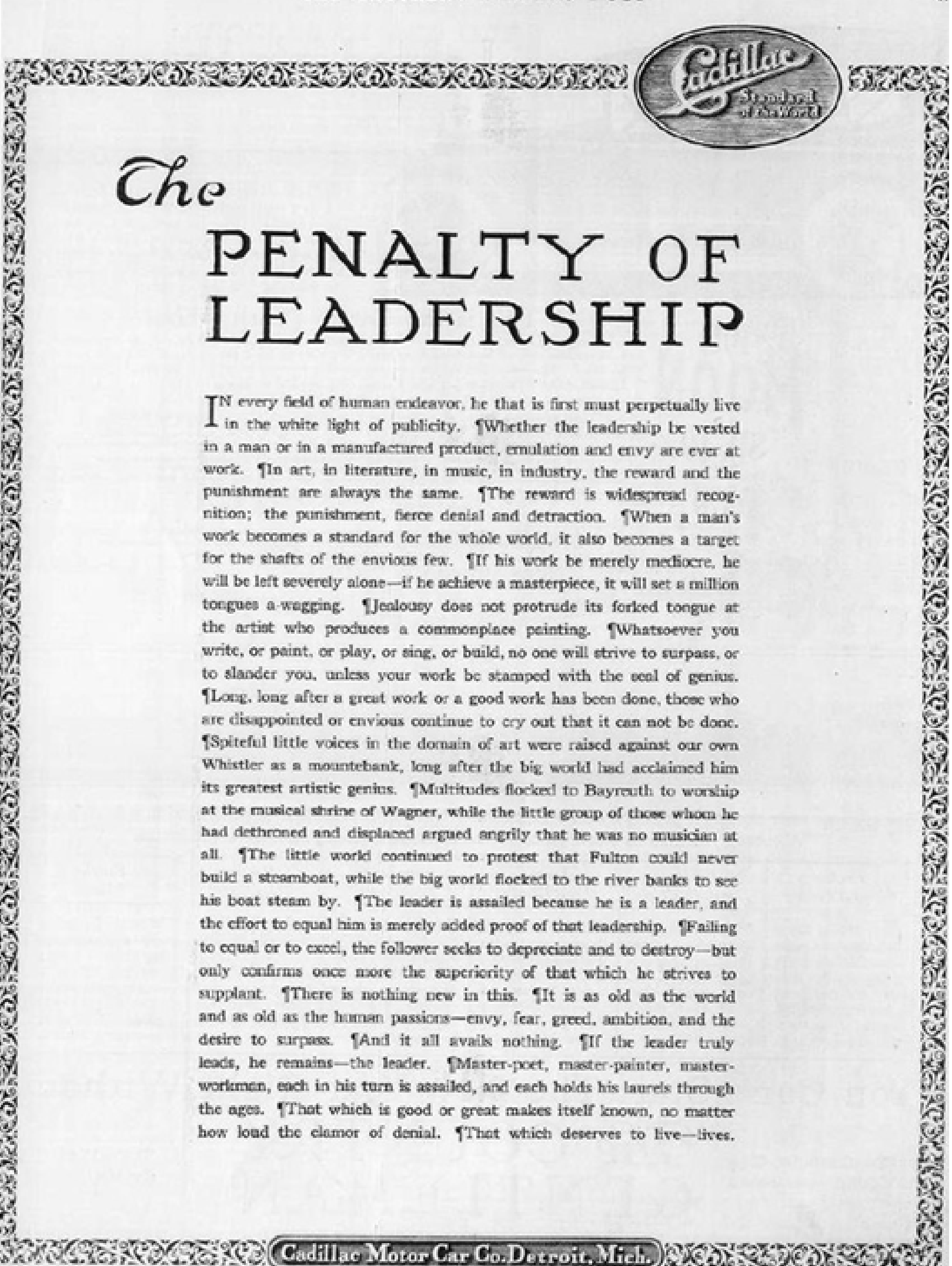

Sponsored Article by Cadillac, Saturday Evening Post, 1915 
In the 1940s, Gillette was the exclusive sponsor for TV and radio's World Series until 1966.

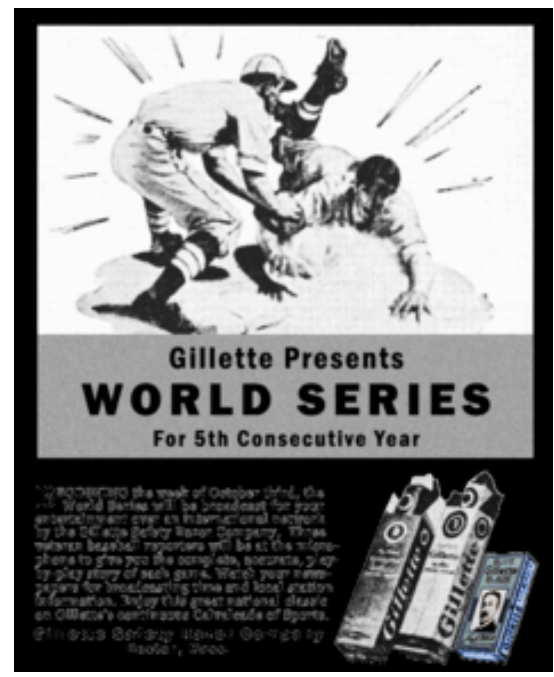

Native advertising had seen its way through the film industry since the 1920 s, known as product placement, the first recorded example was in the 1927 silent movie called "Wings", where Hershey's Chocolate was part of one of the scenes. In 1983, native advertising played as a life saver for the brand "Ray-ban" where Tom Cruise appears in the movie "Risky Business" wearing a pair of black Ray-ban sunglasses, the company sold 360,000 pair of glasses the year the movie was released, after being on the edge of bankruptcy. Hershey's Reese's profits rose by $65 \%$ by appearing in the movie E.T. in 1982. Pizza Hut had also shown success within the world of na- tive advertising by appearing in the 1992 movie "Wayne's World" showing Mike Myers eating pizza from a Pizza Hut box.

Recently Google launched its "Adsense Native Ads", a series of new formats to compliment the content, look and feel of the website. Taking three different formats, Infeed ads that fit inside a list of articles on a specific site; In Article ads where ads appear between paragraphs within the page; and Matched Content which promotes advertiser's content to page visitors, known as a recommendation tool that helps promote content to increase revenue, page views and time spent on site.

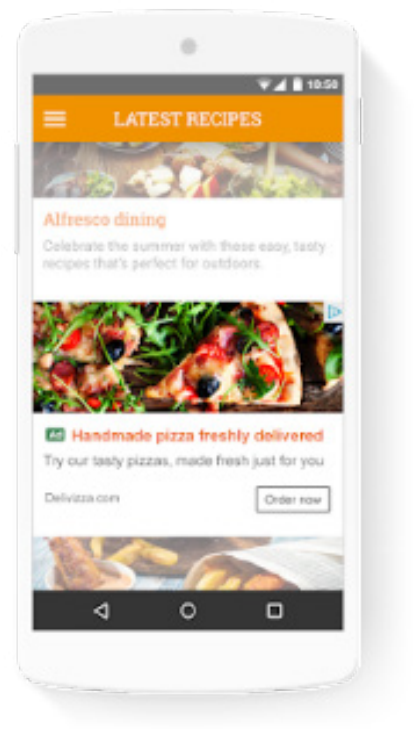

In-Feed Ad

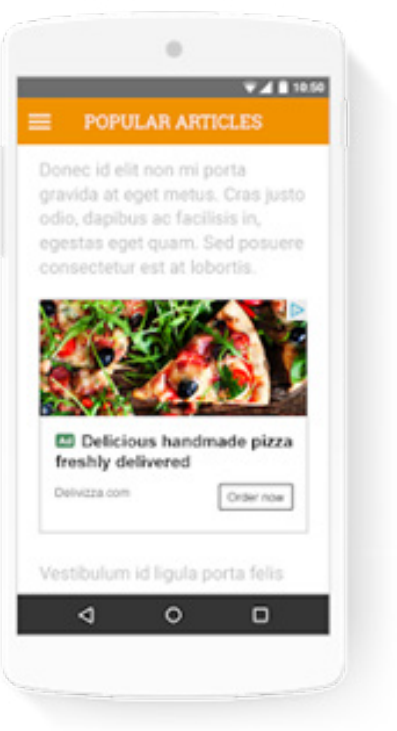

In-Article Ad

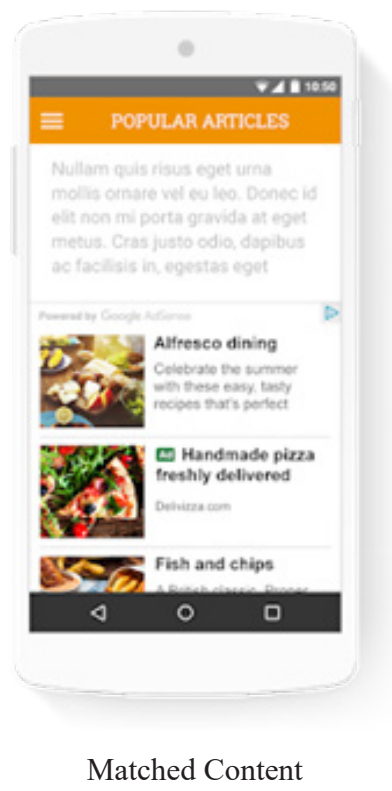

Matched Content 


\section{Goals of Native Advertising}

Digital media and content marketing have been taking the leading position for many brands and campaigns, which has changed the game for marketers for two main reasons. First, digital media has become the most cost-effective platform for brand or product exposure. Second, the potential of reach has increased due to easier distribution based on the fact that one platform allows advertisers to reach target audience internationally having social media acting as the most efficient environment for native advertising.

The main goals of native advertising lie in three main points:

1.Engagement: the advertising message is highly exposed to the target audience without the idea of interruption. As many people skip ads they see on YouTube or other social media videos, native advertising comes integrated within the published article or news, becoming part of what the consumer is reading or looking for.

2.Interaction: the main issue with traditional advertising is that most consumers do not want to respond to them, people usually skip the ad or turn their heads if the ad is not skippable. However, native advertising participates with the consumers in their interests, serving their decisions about products and services.

3.Brand Advocates: the most important aspect is the ability to share native advertising through social media and digital platforms. As target audience have the ability to share the ads within their social circles, the message spreads to a wider range of audience with no extra cost.

Based on these discussed goals, there are three main elements that must be achieved and in place: Reach, Relevance, and Reference. The ad must reach the consumers at the time and place where they are most receptive to the content; the message delivered must be relevant to what the consumer is reading; and the ad needs to be shared and referenced.

Achieving the goals and objectives of native advertising and specific product aims relies on a few points to consider. Content creation is the first step, with a few questions to be answered for creating the content strategy: what is the cam- paign trying to achieve? who are the target audience? what are their preferences? what do they search for and what do they read? Who are your competitors? Second is the choosing of the media platform, it is very important to make sure that the advertising revenue is effectively spent, and that the ad reaches the specified target audience. Third is measurement, the best metrics used to measure effectiveness and performance is consumer engagement. This can be measured through page views, click rates, time spent on the page, social media sharing, brand lifting and cost per click.

\section{Policies, Guidelines and Regulations}

Native advertising is considered as a form of advertising disguised as a non-promotional content. This form of advertising was a major concern for the American Federal Trade Commission, due to the potential deception that would in some cases occur. While FTC did not provide any rules or regulations earlier for native advertising, it was until 2015 when guidelines and policies were issued and enforced. The guidelines entitled: "Native Advertising, A Guide for Business and the Enforcement Policy Statement on Deceptively Formatted Advertisements" come as part of the FTC policies of deception (Federal Trade Commission, 2015a, 2015c), the proposed policies appeared to be proper labeling of content as sponsored or paid advertising (Federal Trade Commission, 2013a). These policies mention that the FTC evaluation of a native ad, it is examining "the net impressions the ad conveys to consumers" (Federal Trade Commission, 2015c, section 1, paragh. 2)

While their remains yet no strict policies specifically for native advertising, the FTC has made it clear that:

1.Transparency is the key concern.

2.In some cases, native advertising is commercial in nature where additional disclosures are not required.

3.If disclosure is necessary to prevent deception, the disclosure must be clear and prominent.

As native advertising seeks to engage with consumers making it feel more like an editorial content rather than an ad, in some cases, it carries a 
possibility to be considered false or misleading, by making unproven claims about the product or service. It might also be considered as misleading by feature or form, if the consumers cannot identify that what they are reading is a form of advertising. Based on FTC, content and the technological context is of great importance in determining the deception of native ads. FTC emphasizes the fact that when it comes to native advertising "the watchword is transparency" (Federal Trade Commission, 2015c, section 1, paragh 6), where transparency is the standard that cuts across content and form.

FTC has decided based on its guidelines that the disclosure of native advertising relies on the context of the content, depending on the placement of the ad within the theme of the designated media platform. Policies state that if the ad contains clear promotional language, directing consumers to find more about the product then these ads are not requiring disclosure. While disclosure would be necessary if the content of the ads addresses topics related to specific products, displaying pictures of the products themselves (Federal Trade Commission, 2015c).

In 2011, The International Chamber of Commerce Consolidated Code on Advertising and Marketing Communication Practice, revised its provisions to include native advertising among its regulations. The ICC recaps the importance of a few guidelines that are vital to ensure transparency and to improve consumer trust, stating the following:

1.Consumers should be able to recognize when something is an ad (ICC Code, art 9, B1, D2)

Article 9: Marketing Communications should be clearly distinguishable as such, whatever their form and whatever the medium used. When an advertisement appears in a medium containing news or editorial matter, it should be so presented that it is readily recognizable as an advertisement and the identity of the advertiser should be apparent. Article B1: Sponsorship should be recognizable as such.

Article D2: The commercial nature of the product endorsements or reviews created by marketers should be clearly indicated and not be listed as being from an individual consumer or indepen- dent body.

2.The identity of an advertiser should be easily ascertainable (ICC Code, art 10, B12)

Article 10: The identity of the marketer should be apparent.

Article B12: Sponsored media properties should be identified as such by presentation of the sponsor's name and/or logo at the beginning, during and/or at the end of the program or publication content. This also applies to online material.

3.Disclosures should be prominent and understandable to consumers (ICC Code, art 3)

Article 3: Marketing communications should be so framed as not to abuse the trust of consumers or exploit their lack of experience or knowledge. Relevant factors likely to affect consumers decisions should be communicated in such a way and at such a time that consumers can take them into account.

The ASME (The American Society of Mechanical Engineers) have updated their general advertising guidelines in 2015 to include native advertising, stating that native advertising on websites and in social media should be clearly labeled as advertising by the use of terms such as "sponsor content" or "paid post" and visually distinguished from editorial content and that collections of sponsored links should be clearly labeled as advertising and visually separated from editorial content. The IAB's (The Interactive Advertising Bureau) Native Advertising Playbook provides disclosure recommendations that are highly consistent with FTC and ASME, stating that disclosures should use language that conveys that the advertising has been paid for, even if that unit does not contain traditional promotional advertising messages, as well as being large and visible enough for a consumer to notice it in the context of a given page and/or relative to the device that the ad is being viewed on (IAB, 2013, pg. 16). Yet, no universal policies or standards are set to govern this type of advertising, while recommendations for native advertising disclosures from policy makers, editorial publishers, and advertisers converge around the FTC's main stays of 
making sure that disclosures are clear enough to be understood and conspicuous enough to be noticed (Wojdynski, 2016, pg. 28).

\section{Native Advertising and Effectiveness}

Since 2013, native advertising has been acting as a vital environment for advertisers, content publishers and different agencies. With continuous yearly growth of revenue with an approximate estimation of $\$ 4$ billion in 2013 to an estimation of $\$ 52$ billion in 2020 (whatsnewinpublishing.com/ may2019). While native advertising is considered being the key to solving digital advertising revenue problems, it has raised parallel apprehensions about the ethics of advertising, its consequences, and how consumers perceive the ads and content publishers. Critics have raised the possibility that the success of native advertising is due in large part to deception of consumers (Colhoun, 2015), which raises a few questions about effectiveness of native advertising. On what basis are consumers reading and clicking on native ads? Is it based on mistaken beliefs that the content is recommended by the publisher? Or is it based on the lack of awareness that native content is actually paid advertising? In reference to Wasserman, 2015, he states that native advertising in short is all about deception. You, as a reader, are encouraged to perceive the messages as something other than what they are. And if at some level, you understand they were put together by the magazines' staff, you are still expected to see them as partaking of the magazine's trustworthiness, and as deserving something of the same regard (Wasserman, 2015).

The visible rise in native ad revenues in the forms of native content and hyperlink listings assumes that advertisers and publishers feel a greater potential for their return on investment, although it has been found that $66.6 \%$ of the consumers felt they have been deceived by sponsored articles posing as standard editorial (Lazauskas, 2014). Since consumers may not recognize that they are being marketed to, they may process the advertising claims differently, in the form of objective information. While consumers who recognize a persuasive attempt may experience negative reactions to the ad and attach negative perceptions to the product (Wojdynski and Evans, 2016). A necessary foundation for the application of persuasion knowledge is the idea of recognition in itself, that the message is an ad, which makes it quite unclear to what degree can consumers recognize native advertising in its different setups.

Disclosures that a given piece of content is in fact paid commercial advertising may also function in a manner similar to other signs of persuasion appeals. Such forewarnings, when presented in a context which allows users to engage in careful thought, can generate resistance to advertising content (Quinn \& Wood, 2004). The manner in which disclosures are presented in native ads is the key dominant of how likely users are to confuse the ads with actual editorial content (Boerman, Reijmersdal, \& Neijens, 2012). The effective disclosure and influence the consumer's process of native ads relies on two main aspects; attention, as the disclosure has to be seen; and comprehension, as the language of the disclosure should clearly articulate the message.

\section{Native Advertising and the Metrics}

Undoubtedly, native advertising has gained a new interest from the researches within the last decade due to the digitalization of the content. All around the world social media penetration increases every year. According to the latest Digital in 2019 report, there are 3.48 billion social media users in 2019 , with the worldwide total growing by 288 million (9 percent) since this time last year. (Digital in 2019). This gives advertisers and marketers good reasons to be interested in the factors effecting the social media behavior. The report also addressed the fact that there are millions of addressable audiences in various platforms, see Figure 3. Social media platforms fight between each other to have the best result-oriented approach to the advertisers, various social media platforms were. 


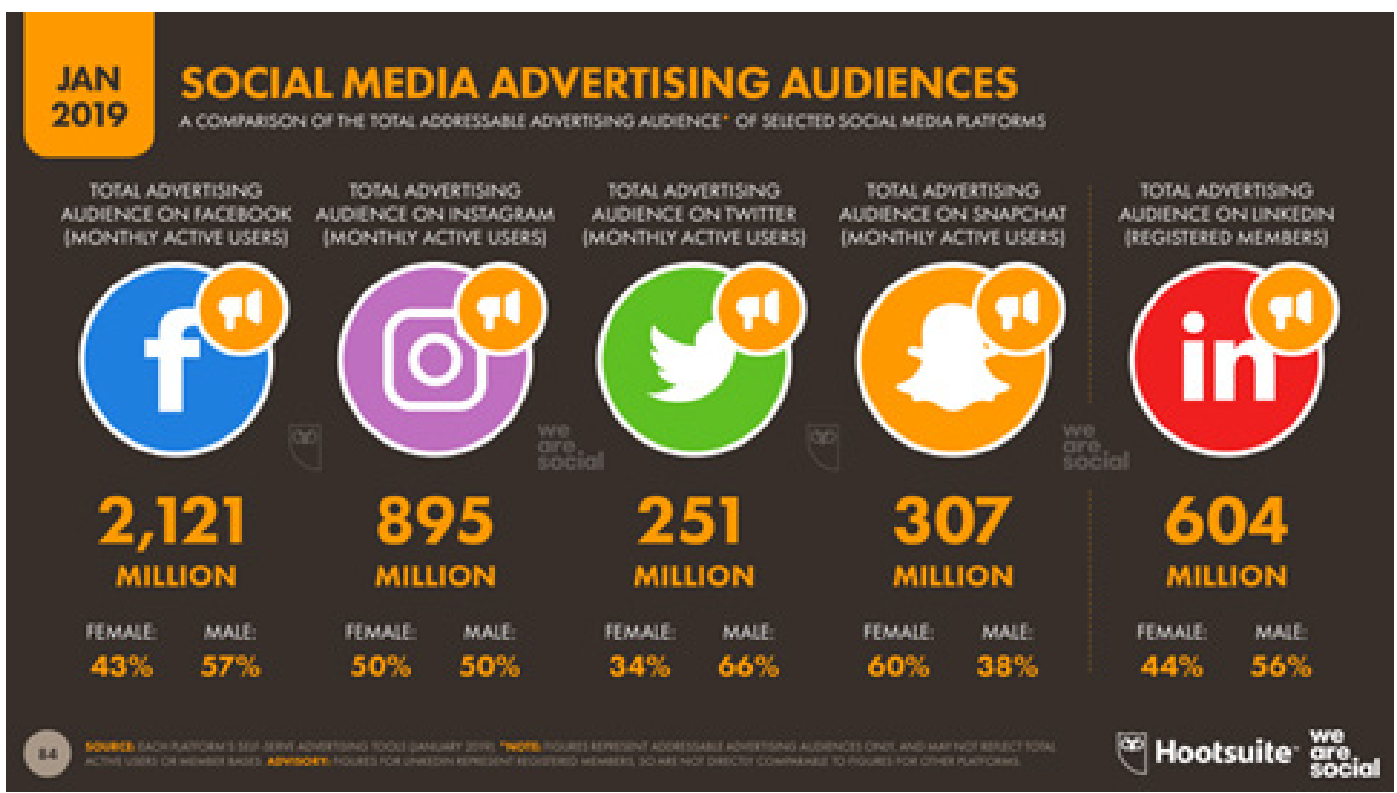

Figure 3. Social Media Advertising Audiences, 2019

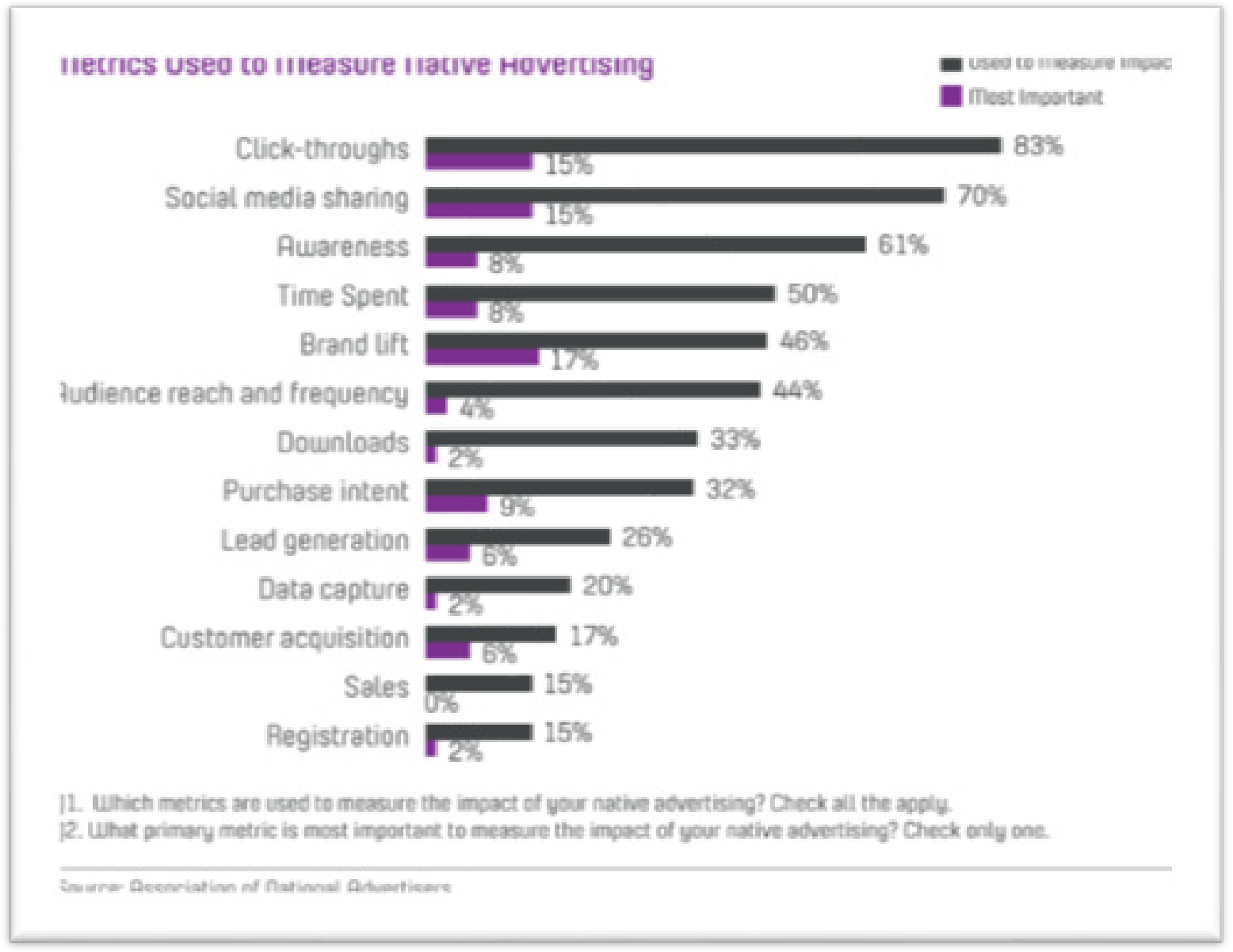

Figure 4. Metrics Used to Measure Native Advertising 
One of the important phenomena that causes a big debate amongst advertising researchers is the consumer engagement and its return on investment in digital marketing. The more native budget increases the publishers still remain confused about the metrics as well. So far, no single metric has been labeled both by practitioners or by scholars as the "crucial" metric to measuring native advertisings' effectiveness. The main reason that the engagement cannot be measured perfectly is due to the variety of metrics used to measure the impact. It is also crucial to understand the campaigns goal before even deciding on the tracking measurement. Once the goals are defined, it becomes easier for an advertiser to decide on the metric. According to a recent study conducted by Association of National Advertisers, see Figure 4. Below, found that the most of advertisers use click-throughs and social media sharing as a main metric to measure impact of native advertising. An interesting finding proved the clickthrough was conducted with more than 18 billion native ads across 5,000 branded content programs (including publishers like The Washington Post, Gannett, and AOL) showed that click-through rates (CTR) for premium native ads were highest on smartphones, at $0.38 \%$ in 2015 .

According to a Forbes journalist Jonathan Long, the biggest advantage native ads for publishers is the amount of control they maintain over their site's content. Oftentimes, if a website is allowing banner ads, the advertiser is in control, not the publisher. Websites can also maintain their existing style and tone with native advertising. They don't have to compromise their layout in order to monetize their content.(Long, 2016)

\section{Native Advertising and Content Creation}

After metrics the second important phenomena in native advertising in the digital era is the content creation process. Content marketing and Native Advertising are sometimes confused as they overlap in some way in their nature. Content marketing is a marketing strategy focused on the constant development and dissemination of useful, important and enticing content to meet our target audience. The ultimate goal, like other forms of advertising, is to influence the customer in order to increase the sales. Below table explains the differences between content marketing and native advertising.

\begin{tabular}{|l|l|l|}
\hline \multicolumn{1}{|c|}{ Factors } & \multicolumn{1}{c|}{ Content Marketing } & \multicolumn{1}{c|}{ Native Advertising } \\
\hline Goals & $\begin{array}{l}\text { Search Engine Rankings } \\
\text { Brand Awareness }\end{array}$ & $\begin{array}{l}\text { Social Engagement } \\
\text { Brand Awareness }\end{array}$ \\
\hline KPIs & $\begin{array}{l}\text { Number of Leads } \\
\text { Total Social Shares }\end{array}$ & $\begin{array}{l}\text { Social Engagement } \\
\text { Campaign Views }\end{array}$ \\
\hline Channels & Average of 27 publisher stories & 1 publishing partner \\
\hline Benefits & $\begin{array}{l}\text { Increased organic rankings } \\
\text { Brand awareness }\end{array}$ & $\begin{array}{l}\text { Brand engagement } \\
\text { Brand awareness }\end{array}$ \\
\hline Challenges & Requires long-term investment & "Sponsored "tag perceived as ad \\
\hline
\end{tabular}

Table 1. Content Marketing vs Native Advertising, Adapted from Dr4Ward. 
Researchers agree that if you make really compelling content and have the brand as a part of the content and also have something which really matters to the consumer you can have a lot of success.( Rishi et al, 2016). Creating content which resonates with people and stays in consumers mind longer than 5 minutes is considered as success nowadays. Especially if you are targeting Millennials and Gen- $Z$ your task is much harder. (Florenthal, 2019) In his very recent study, Huang examined the relationship of leveraging native advertising in terms of content creation and platform selection on social media, proposing that variations in content and platform reduce the intrusiveness of native ads. The results of this study showed that content strategy plays a crucial role as a boundary condition for the cross-platform advantage while creating native advertising in social media platforms such as Facebook, Instagram and Twitter. (Huang, 2019). Another recent study also proved that the advertisers must focus on creating a compelling storytelling that engages the consumer in a way that the consumers observe, understand and respond positively to them. If this could be achieved by brands they can understand the effect of their content.(Brandão et al, 2019). Content type in native advertising plays important role as well. Latest study of Harms et al confirmed that the if the consumer understands the message the intent of the message is stronger for banners than article-style native advertisements. Banner ads are which are used widely in digital media lead to stronger positive associations than article-style native advertisements. (Harms et al., 2019)

Native Advertising and Online Consumer Behavior A study in American Behavioral Scientist found that consumers are more and more embraced by native advertising, especially if they are sponsored by a company that has a strong relationship with customers or if the advertisements offer information to the consumer According to Sweetser, the participants inclined to stay on the page for an average of eight minutes even though they knew it was a sponsored advertisement.( Sweetser, 2016) The growing trend in the area of native advertising can be seen in the below Figure of Google Trends data. Since 2014 the increase in online platforms have been tremendous.

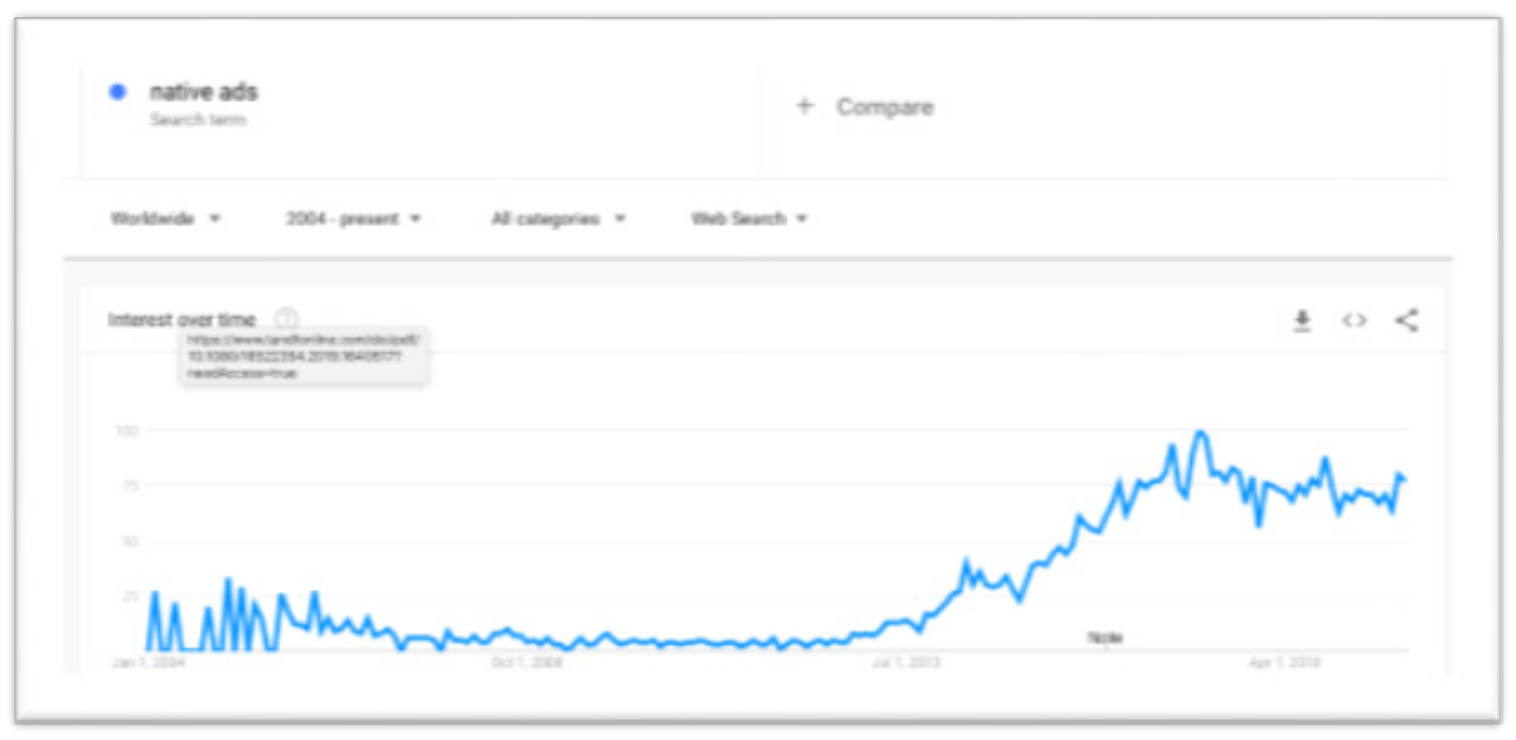

Figure 5. Google Trends Search Results for Native Ads.

Scholars agree that the goal of native advertising is to contribute in a way that doesn't disrupt the user experience. The native ad should be useful, stimulating, and highly relevant to audience. (Merunka, 2007). Other important criteria that effects the positive consumer reaction is the relationship between the design and the layout of the webpage. Native advertising works if the ad is delivered in the same format as the content around it. To be a working native ad, it must look and feel like it belongs and resonates with the au- dience. Nowadays the consumer has the utmost power and the voice. They decide what they want to see and interact with it. In order to stay in the long-term memory of the consumers is very challenging. It requires a combination of factors from language, pre and post knowledge of the brand, social media type and others. (Noguti, 2016). 


\section{Conclusion:}

In conclusion, this exploratory study contributes to the literature of discussions about the native advertising and its future in marketing. It becomes crucially important for advertisers to understand that the consumers nowadays are more sceptic than ever. They do not want their time to be wasted with fake ads, fake reviews or fake practices. Especially the younger generations have a magical chip to understand what is fake and what is authentic. Therefore, the publishers need to be very careful while selecting their strategy on developing native advertising. The following quote sums up our findings suitably:

"A lot of people have the impression that ads can just appear as part of editorial and in some way hide. The exact opposite is what makes good native advertising." Clare O'Brien, Internet, Advertising Bureau

\section{References:}

1.Boerman, S.C., Reijmersdal, E.A., \& Neijens, P.C. (2014). Effects of Sponsorship Disclosure Timing on the Processing of Sponsored Content: A Study on the Effectiveness of European Disclosure Regulations. Psychology and Marketing, 31(3), 214-224.

2.Brandão, A., Pinho, E., \& Rodrigues, P. (2019). Antecedents and consequences of luxury brand engagement in social media. Spanish Journal of Marketing-ESIC. Digital in 2019, Retrieved from: https://wearesocial.com/uk/digital-2019

3.Colhoun, D. (2015, February 10). Disguising ads as stories. Columbia Journalism Review. Retrieved from http:// www.cjr.org/behind_the_news/sponsored_content.php 4.Federal Trade Commission. (2015). Federal Registrar. Vol. 80, No. 6. January 9, 2015/Rules and Regulations

5.Florenthal, B. (2019). Young consumers' motivational drivers of brand engagement behavior on social media sites. Journal of Research in Interactive Marketing.

6.Giller, E. (2016). Native Advertising: An International Perspective. Professional Projects from the College of Journalism and Mass Communications.

7.(http://digitalcommons.unl.edu/journalismprojects/7)

7.Harms, B., Bijmolt, T. H., \& Hoekstra, J. C. (2019). You don't fool me! Consumer perceptions of digital native advertising and banner advertising. Journal of Media Business Studies, 1-20.

8.http://Iab.com/wp-content/uploads/2015/07/IAB_AnnualReport2013

9.Huang, G. (2019). Variation matters: How to curb ad in- trusiveness for native advertising on Facebook, Twitter, and Instagram. Internet Research.

10.ICC Guidance on Native Advertising. Commission on Marketing and Advertising (May 2015) Document No. 240712. $\mathrm{MCB} /$ sto 6 .

11.Laursen, J. (2017). Native Advertising Trends in News Media. Native Advertising Institute, December 2017.

12.Lazauskas, J. (2014, July 9). Study: Sposored content has a trust problem. Retrieved from http://contently.com/strategist/2014/07/09/study-sponsored-content-has-a-trust-problem-2/

13.Long, J., 2016. How Native Ads Can Benefit Both Advertisers And Publishers Retrieved from: https://www.forbes. com/sites/theyec/2016/11/04/how-native-ads-can-benefit-both-advertisers-and-publishers/\#62f137734447)

14.Manic, M. (2015). The Rise of Native Advertising. Series V: Economic Sciences, Vol. 8 (57) No. 1

15.Merunka, D. R., \& Peterson, R. A. (2007). Language, thought, and consumer research. In Review of Marketing Research(pp. 152-192). Emerald Group Publishing Limited. 16. Noguti, V. (2016). Post language and user engagement in online content communities. European Journal of Marketing, 50(5/6), 695-723.

17.Quinn, J.M., \& Wood, W. (2004). Forewarnings of influence appeals: Inducing resistance and acceptance. In E.S. Knowles \& J.A. Linn. Resistance and Persuasion (pp. 193213). Mahwah, NJ: Erlbaum.

18.Rishi, B., Mehta, A., Banerjee, P., \& Deepak, A. (2018). Buzzfeed Inc: native advertising the way forward?. Emerald Emerging Markets Case Studies, 8(4), 1-18.

19.Sweetser, K. D., Ahn, S. J., Golan, G. J., \& Hochman, A. (2016). Native advertising as a new public relations tactic. American behavioral scientist, 60(12), 1442-1457.

20.Wasserman, E. (2013, April 1). Advertising goes native, and deception runs free. Huffington Post. Retrieved from http://huffingtonpost.com/edward-wasserman/native-advertising-atlantic-scientology_b_2575945.html

21.Wodjdynski, B.W. \& Evans, N.J. (2016) Going Native: Effects of disclosure position and language on the recognition and evaluation of online native advertising. Journal of Advertising, 45 (2), 157-168

22.Wojdynski, B.W. (2016). Native advertising: Engagement, deception, and implications for theory. In R. Brown, V.K. Jones, and B.M. Wang (Eds.), The New Advertising: Branding, Content and Consumer Relationships in a Data-Driven Social Media Era (pp.203-236). Santa Barbara, CA: Praeger/ABC Clio 